\title{
Disordered axial movement in Parkinson's disease
}

\author{
M J Steiger, P D Thompson, C D Marsden
}

\begin{abstract}
Axial motor impairments are a common cause of disability in patients with Parkinson's disease, become more prominent with longer disease duration, and have been said to be less responsive to levodopa replacement therapy. The ability to turn in bed while lying supine before and after dopaminergic stimulation was studied in a group of 36 patients with Parkinson's disease; 23 were in Hoehn and Yahr stages 3-5 when "off", and 13 were in stages 1-2. Turning was also compared with postural stability and gait before ("off") and after ("on") dopaminergic stimulation. Failure to turn in bed was noted in 19 of the 36 patients in the "off" state, with significant associations between disturbances of gait, postural stability, rising from a chair, whole body bradykinesia, and axial rigidity. Gait, postural stability, rising from a chair, whole body bradykinesia, and axial rigidity were significantly correlated in the "off" state. Disorder of axial movement, gait, and postural stability were not dependent on age at onset of Parkinson's disease, but did relate to duration of disease. After a levodopa challenge, turning in bed returned to normal in all but one patient, and gait, postural stability, rising from a chair, whole body bradykinesia, and axial rigidity also improved in nearly all. It is concluded that in the later stages of Parkinson's disease at least some aspects of axial motor control can remain dopamine responsive.
\end{abstract}

(F Neurol Neurosurg Psychiatry 1996;61:645-648)

University Departmen of Clinical Neurology, Institute of Neurology, National Hospital for Neurology and

Neurosurgery, Queen

Square, London WC1N 3BG, UK

M J Steiger

P D Thompson

C D Marsden

Correspondence to:

Dr M J Steiger, Walton

Centre for Neurology and

Centre for Neurology and

Neurosurgery, Rice Lane,

Received 10 August 1995

and in final revised form

3 June 1996

Accepted 16 July 1996

Keywords: Parkinson's disease; axial movements; limb bradykinesia; axial bradykinesia

Levodopa therapy for Parkinson's disease produces obvious improvements in motor function. Tremor, rigidity, and bradykinesia respond dramatically; but with advancing disease disorders of speech, postural equilibrium, and gait may not improve at all or only partially. ${ }^{1.4}$

Many patients with Parkinson's disease experience difficulty turning over in bed. This difficulty in turning when lying flat is due to inability to execute the sequence of axial movements required to achieve the task. The motor pathways controlling axial movements (reticulospinal and vestibulospinal ${ }^{56}$ ) are different from those controlling distal limb movements (corticospinal tracts). Axial muscles are also involved in the maintenance of posture and in locomotion. One aim of the present study, therefore, was to assess whether there is a correlation between an inability to turn in bed and postural instability and locomotion difficulties in Parkinson's disease.

The clumsy sequences of movements adopted by parkinsonian patients to shift their centre of gravity and achieve a change in posture have been called an "apraxia of axial movements" by Lakke et al. ${ }^{79}$ Twenty five per cent of patients showed no benefit with levodopa. $^{7}$

A second aim of this study, therefore, was to compare the effect of levodopa on the ability to turn over in bed, on postural equilibrium, and on gait in patients with Parkinson's disease. In addition, the effects of levodopa on these axial disabilities were compared with its effects on tremor, bradykinesia, and rigidity in the limbs.

\section{Method}

The Parkinson's disease group consisted of 36 patients of mean age $55 \cdot 4$ (SD 10.5); range 32 to 76 years and duration of disease 10.9 (SD $6 \cdot 7)$; range 2 to 28 years. Three patients were Hoehn and $\mathrm{Yahr}^{10}$ stage $5 ; 12$ patients stage 4; eight patients stage $3 ; 12$ patients stage 2 , and one patient stage 1 , when examined in the "off" state. All responded to levodopa treatment. After overnight drug withdrawal, all patients were assessed when "off" with the King's College Hospital (KCH) rating scale. ${ }^{11} 12$ All the patients were attending the National Hospital for Neurology and Neurosurgery.

In the $\mathrm{KCH}$ rating score, subscores are 
Table 1 Comparison of parkinsonian features when "off" in patients with and without difficulty in turning over in bed (DTB)

\begin{tabular}{|c|c|c|c|}
\hline Characteristics & $\begin{array}{l}\text { No DTB } \\
(n=17)\end{array}$ & $\begin{array}{l}D T B \\
(n=19)\end{array}$ & Pvalue \\
\hline $\begin{array}{l}\text { Age at study (y) } \\
\text { Duration of disease (y) } \\
\text { Age at onset }(y)\end{array}$ & $\begin{array}{c}51 \cdot 3(11 \cdot 3) \\
7 \cdot 1(5 \cdot 2) \\
44 \cdot 3(10 \cdot 0)\end{array}$ & $\begin{array}{l}58 \cdot 9(8 \cdot 8) \\
14 \cdot 3(6 \cdot 2) \\
44 \cdot 7(9 \cdot 0)\end{array}$ & $\begin{array}{l}\text { NS } \\
<0.005 \\
\text { NS }\end{array}$ \\
\hline $\begin{array}{l}\mathrm{KCH} \text { rating } \\
\text { Hoehn and } \mathrm{Yahr}\end{array}$ & $\begin{array}{l}32(13) \\
2 \cdot 4(0 \cdot 6)\end{array}$ & $\begin{array}{l}58(16) \\
3 \cdot 7(0 \cdot 9)\end{array}$ & $\begin{array}{l}<0.001 \\
<0.01\end{array}$ \\
\hline $\begin{array}{l}\text { Rising from a chair } \\
\text { Postural stability } \\
\text { Gait } \\
\text { Axial rigidity } \\
\text { Whole body bradykinesia }\end{array}$ & $\begin{array}{l}0.4(0.5) \\
0.8(0.8) \\
0.9(0.7) \\
0.9(0.7) \\
1.3(0.6)\end{array}$ & $\begin{array}{l}1 \cdot 9(0 \cdot 9) \\
2 \cdot 2(0 \cdot 8) \\
2 \cdot 1(0 \cdot 7) \\
1 \cdot 9(0 \cdot 6) \\
2 \cdot 3(0 \cdot 6)\end{array}$ & $\begin{array}{l}<0.001 \\
<0.005 \\
<0.001 \\
<0.005 \\
<0.001\end{array}$ \\
\hline $\begin{array}{l}\text { Limb rigidity } \\
\text { Limb bradykinesia } \\
\text { Limb tremor }\end{array}$ & $\begin{array}{l}1.5(0.9) \\
1.3(0.6) \\
0.6(0.7)\end{array}$ & $\begin{array}{l}1.9(0 \cdot 7) \\
2 \cdot 0(0 \cdot 7) \\
1 \cdot 2(0.9)\end{array}$ & $\begin{array}{l}\text { NS } \\
\text { NS } \\
\text { NS }\end{array}$ \\
\hline
\end{tabular}

For age, duration of disease, age at onset of disease, and $\mathrm{KCH}$ values are means (SD). For Hoehn and Yahr scale and the subscores of the $\mathrm{KCH}$ rating, values are median (quartile).

the scores of the rating of rising from a chair, postural stability, gait, axial rigidity, and whole body bradykinesia. Limb score was taken as the mean of the scores of the ratings of limb rigidity, limb tremor, and limb bradykinesia.

Lakke et $a l^{7}$ judged turning in bed to be normal if it was initiated by the head and shoulder, not the pelvis and leg. Pushing with the free hand against the floor behind, or not using the free arm at all were assessed as abnormal. Pronounced flexion of the knee early in turning was also scored as abnormal. However, the findings of Cox et $a l^{13}$ and Steiger and Berman ${ }^{14}$ in a healthy non-parkinsonian population suggest that there is a wide variation in trunk turning in normal subjects. We therefore devised strict criteria to assess the ability to turn over in bed. Patients were requested to lie on a bed (or the floor) and turn over from supine to the left and right through $90^{\circ}$ while closely watched. The instruction given was "turn on to your side", followed by an instruction to turn to the other side. Patients were told that they were not allowed to sit up to turn. Truncal movements were considered abnormal if the patient turned over using the free hand to push the trunk over, or if the patient sat up before turning. Failure to swing the free arm or flexion of the knees in turning was considered acceptable if by doing so the patient was able to turn, as normal subjects have been seen to adopt such a strategy. ${ }^{14}$ Turning over in bed was categorised as either normal or abnormal on these criteria.

All patients were also requested to stand from sitting. Patients were allowed to use their arms to help lift themselves from the sitting position. No verbal or physical help was offered.

After baseline assessment, all patients were given a levodopa challenge with either Madopar 250 or two Sinemet 25/100, and reassessed as above after turning "on". Similar observations were also made in 10 patients with other parkinsonian syndromes (six with multiple system atrophy and four with progressive supranuclear palsy).

\section{STATISTICAL METHODS}

Differences in demographic characteristics in the subgroups of patients were examined with independent $t$ tests. Categorical data were analysed with a $\chi^{2}$ test. Considering the number of comparisons, a stringent value of significance was adopted for all analyses. $P$ values $\leqslant 0.01$ were considered significant. The association between variables (for example, disease duration and postural stability) in both the "on" and "off" states was assessed with Spearman rank correlations. A stringent level of significance of $r<0.05$ or $\mathrm{P}<0.005$ was employed.

For age, disease duration, age at onset of disease, and $\mathrm{KCH}$ rating significance was assessed by Student's $t$ test. For Hoehn and Yahr scale and the subscores of the $\mathrm{KCH}$ rating, significance was determined by $\chi^{2}$ test.

\section{Results}

TURNING IN BED

Nineteen of the 36 patients with Parkinson's disease had difficulty turning in bed in the "off" state, including nine who were entirely unable to change position. The other 10 patients adopted an unusual method to achieve the final position. For example, lifting the trunk and sitting up before turning or trying to push the trunk over with the free extended arm.

The patients with difficulty turning in bed were of similar age and age of onset of their disease compared with the group without such problems, but had longer duration of disease (table 1). They were more severely affected as assessed by the $\mathrm{KCH}$ rating scale when "off", and Hoehn and Yahr stage. Postural stability, rising from a chair, and gait were all significantly worse in those with difficulty turning in bed (table 1). They also had greater axial rigidity and whole body bradykinesia. The manifestations of axial impairments were all highly correlated in the "off" state after levodopa withdrawal (Spearman rank correlation coefficents between scores on axial items were in the range 0.59 to $0.81 ; \mathrm{P}<0.005$ to 0.001 ). However, the correlations between limb and axial impairments were either not significant, or less strongly correlated. For example, there was no association of limb tremor with axial motor ratings, whereas limb bradykinesia was significantly associated with axial rigidity $(r=$ 0.62 ) but not with limb bradykinesia or postural stability. Furthermore, patients with difficulty turning in bed did not have greater limb rigidity, tremor, or limb bradykinesia (table 1).

\section{EFFECT OF LEVODOPA ON MOTOR RATING}

Only one of the 19 patients with Parkinson's disease had persisting difficulties in turning in bed after levodopa. His $\mathrm{KCH}$ rating scale fell by less than $50 \%$ after comparing the "on" score with the "off", suggesting only a partial response to the dose given. In the other 18 patients, turning over in bed was restored to normal by levodopa. Other axial impairments also showed an excellent response to levodopa (table 2).

\section{OTHER AKINETIC-RIGID SYNDROMES}

Of the 10 patients with other parkinsonian syndromes five of the six patients with multi- 
Table 2 Effect of levodopa (Madopa 250 or two Sinemet 25/100) on posture, gait, and axial mobility in patients with Parkinson's disease with and without difficulty in turning over in bed (DTB)

\begin{tabular}{|c|c|c|c|c|}
\hline & \multicolumn{2}{|c|}{ No DTB $(n=17)$} & \multicolumn{2}{|c|}{$D T B(n=19)$} \\
\hline & “Off" & “On" & “Off” & “On" \\
\hline $\begin{array}{l}\text { Rising from a chair } \\
\text { Postural stability } \\
\text { Gait disorder } \\
\text { Axial rigidity } \\
\text { Whole body bradykinesia }\end{array}$ & $\begin{array}{l}0.4(0.5) \\
0.8(0.8) \\
0.9(0.7) \\
0.9(0.7) \\
1.2(0.6)\end{array}$ & $\begin{array}{l}0 \cdot 1(0 \cdot 5) \\
0 \cdot 1(0 \cdot 2) \\
0 \cdot 1(0 \cdot 3) \\
0 \cdot 1(0 \cdot 3) \\
0 \cdot 1(0 \cdot 2)\end{array}$ & $\begin{array}{l}1.9(0.9) \\
2 \cdot 2(0 \cdot 8) \\
2 \cdot 1(0 \cdot 7) \\
1.9(0.6) \\
2 \cdot 4(0.6)\end{array}$ & $\begin{array}{l}0.4(0.6) \\
0.8(0.9) \\
0.7(0.7) \\
0.3(0.5) \\
0.6(0.6)\end{array}$ \\
\hline
\end{tabular}

Values are subscores of the $\mathrm{KCH}$ rating given as median (quartile).

ple system atrophy, and two of the four patients with progressive supranuclear palsy had difficulty turning in bed. Levodopa improved turning in bed in only one patient with multiple system atrophy and none of those with progressive supranuclear palsy.

\section{DISCUSSION}

We have shown that difficulty in walking, postural stability, rising from a chair, whole body bradykinesia, axial rigidity, and ability to perform axial sequences such as turning over in bed are highly intercorrelated in patients with Parkinson's disease in the "off" state. The age of onset of Parkinson's disease and the age at the time of study did not seem to influence most of these axial impairments. With increasing duration of disease however, patients were more likely to be more severely disabled with more prominent axial rigidity, difficulty rising from a chair, and turning over in bed.

Difficulty turning over in bed is clearly part of the overall problem of axial motor impairments in Parkinson's disease. The question arises as to whether this difficulty, and other axial movement disturbances, are true apraxias, as implied by Lakke et al..$^{7-9}$ Attempts have been made to establish whether the disorder of generating motor sequences in patients with Parkinson's disease relates to classic tests of limb apraxia. Cox et $a^{13}$ studied 40 patients with Parkinson's disease and found no association of disordered truncal movements with limb apraxia, or with severity (as assessed by Webster rating), or with duration of Parkinson's disease. This suggests that the difficulty in turning over in bed is not apraxic. The profound slowness and disruption of sequences of limb and axial movement required to turn in bed provides sufficient explanation for the difficulty. Furthermore, the correction by levodopa places it in the category of core Parkinson's disease deficits.

Why is there a breakdown of the axial movement sequence in turning over in untreated patients with Parkinson's disease? Bedside observations suggest that the difficulties arise from adopting inappropriate turning strategies. One example is using the free hand to push the trunk over. The disruption of limb and axial movement sequences engaged when turning in bed may manifest as unusual or new strategies that were once undertaken automatically. Automatic associated movements are also involved in Parkinson's disease. The loss of arm swing when walking being another example of disruption of limb-axial automatic movement sequence.
By analysing subscores of the $\mathrm{KCH}$ rating scale it is possible to separate those characteristics which affect control of axial movements (gait, equilibrium, axial rigidity, rising from a chair, turning in bed, and whole body bradykinesia) from those predominantly affecting the limbs (limb tremor, limb rigidity, and limb bradykinesia). There were significant intercorrelations in each of the subgroups, but weaker correlations between axial and limb subscores of the $\mathrm{KCH}$ rating scale. This is consistent with the notion that bradykinesia represents loss of the capacity to perform sequences of movement. It also suggests that this is not uniform across different anatomical parts of the motor system, indicating that control of axial and limb movements are anatomically distinct.

It has been suggested that there is innervation of axial and proximal musculature via a "postural" motor column partly arising from the superior portion of area 6 (supplementary motor area $)^{15}$ that projects to the ventromedial grey matter of the spinal cord ${ }^{16}$ and eventually terminates primarily at axial and girdle motor neurons. ${ }^{17}$ Therefore, it is possible to conceive of two aspects of postural and locomotor activity. Firstly, the more reflex mechanisms subserved by brainstem spinal systems. Secondly, the more voluntary activities, which, as discussed above, might include such aspects as turning over in bed or rising from a chair. It is possible that pathology in Parkinson's disease might differentially affect these two aspects of control of posture and locomotion.

Our findings indicate that such axial movement control is influenced by striatal dopaminergic activity. However, postural stability and gait disturbances were somewhat less responsive to such dopaminergic stimulation, a finding consistent with reports from other groups. ${ }^{1-4}$ The lack of a benefit after levodopa in axial movement sequences in patients with other akinetic-rigid syndromes (such as multiple system atrophy or progressive supranuclear palsy) is striking, suggesting that this is due to degeneration in systems less affected in Parkinson's disease. Perhaps these are the brainstem postural and locomotor centres.

1 Koller WC, Glatt S, Vetere-Overfield B, Hassanein R. Falls and Parkinson's disease. Clin Neuropharmacol 1989; 12:98-105.

2 Bonnet A-M, Loria Y, Saint-Hilaire M-H, Lhermitte F, Agid Y. Does long-term aggravation of Parkinson's disease result from nondopaminergic lesions? Neurology 1987;37:1539-42.

3 Klawans HL. Individual manifestations of Parkinson's disease after ten or more years of levodopa. Mov Disord ease after ten
$1986 ; 1: 187-92$.

4 Zetusky WJ, Jankovic J, Pirozzolo FJ. The heterogeneity of Parkinson's disease: clinical and prognostic implications. Neurology 1985;35:522-6.

5 Lawrence DG, Kuypers HGJM. The functional organization of the motor system in the monkey. I. The effects of bilateral pyramidal lesions. Brain 1968;91:1-14.

6 Lawrence DG, Kuypers HGJM. The functional organization of the motor system in the monkey. II. The effects of lesions of the descending brain-stem pathways. Brain 1968;91:15-33.

7 Lakke JPWF, de Jong PJ, Koppejan EH, van Weerden TW. Observations on postural behaviour: axial rotation in recumbent position in Parkinson patients after L-dopa treatment. In: Rinne UK, Klinger M, Stamm G, eds. Parkinson's disease-current progress, problems and management. Amsterdam: Elsevier/North Holland Biomedical Press, 1980:187-96. 
8 Lakke JPWF, van Weerden TW, Stall-Schreinemachers A Axial apraxia, a distinct phenomenon. Clin Neurol Axial apraxia, a distinct

9 Lakke JPWF. Axial apraxia in Parkinson's disease. 7 Neurol Sci 1985;69:37-46.

10 Hoehn MM, Yahr MD. Parkinsonism: onset, progression and mortality. Neurology 1967;7:427-42.

11 Parkes JD, Zilkha KJ, Calver DM, Knill-Jones RP. Controlled trial of amantadine hydrochloride in Parkinson's disease. Lancet 1970;i:259-62

12 Quinn NP, Marsden CD, Parkes JD. Complicated response fluctuations in Parkinson's disease: response to intravenous infusion of levodopa. Lancet 1982;ii: 412-5.
13 Cox JGC, Pearce I, Steiger MJ, Pearce JMS. Disordered axial movement in Parkinson's disease-a true apraxia? In: Rose FC, ed. Current problems in neurology. Vol 6. London: John Libbey, 1987:71-5.

14 Steiger MJ, Berman P. Gait disturbances in the acute medically ill elderly. Postgrad Med F 1993;69:141-6.

15 Murray EA, Coulter JD. Organization of corticospinal neurons in the monkey. $\mathcal{F}$ Comp Neurol 1981;195:339-65.

16 Kuypers HGJM. The descending pathways to the spinal cord, their anatomy and function. Prog Brain Research 1964;11:178-202.

17 Kuypers HGJM, Brinkman J. Precentral projections to different parts of the spinal intermediate zone in the rhesus monkey. Brain Res 1970;24:29-48. 